\title{
Glucocorticoid receptor mutations and clinical sensitivity to glucocorticoid in Chinese multiple sclerosis patients
}

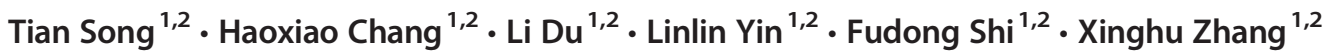

Received: 6 September 2019 / Accepted: 26 March 2020 / Published online: 10 April 2020

(C) The Author(s) 2020

\begin{abstract}
Background Glucocorticoid (GC) is the first-line therapy in acute attacks of multiple sclerosis (MS), but its efficacy is individually variable and may be associated with glucocorticoid receptor $(G R)$ gene.

Objective To establish the association between GR gene sequence and clinical GC sensitivity in Chinese MS patients. And to investigate the expression differences of serum GR $\alpha$ and FK506 binding protein 5 (FKBP5) in GC responders and non-responders. Materials and methods Coding exons 2-9 of the $G R$ gene from $97 \mathrm{MS}$ patients were sequenced. We performed ELISA to detect serum GR $\alpha$ and FKBP5 before the GC impulse therapy in patients with different GC sensitivities (according to the EDSS changes before and after the GC medication).

Results Seven new mutations were located in exon 2, but the presence or absence of mutations was not associated with the response to GC therapy $(P=0.416)$. The GC-sensitive patients had higher GR $\alpha(P=0.011)$ but lower FKBP5 $(P=0.025)$ levels in the serum. Conclusions The $G R$ mutations detected in our study were not associated with the response to GC in Chinese MS patients. Higher $\mathrm{GR} \alpha$ and lower FKBP5 levels in the serum might predict the response to GC, which may provide potential therapeutic target for GC-resistant patients with acute MS attack.
\end{abstract}

Keywords Glucocorticoid receptor $\cdot$ Mutations $\cdot$ GR $\alpha \cdot$ FKBP5 $\cdot$ Multiple sclerosis

\section{Introduction}

Multiple sclerosis (MS) is an inflammatory disease of central nervous system (CNS) which generally begins in early adulthood. Glucocorticoids (GC) have anti-inflammatory and immunosuppressive properties and are thus recommended as the firstline therapy in the management of acute attacks of MS [1]. However, in the clinical practice, we found individual variability in GC efficacy. Some patients were resistant to GC initially, but in some other patients, the response to $\mathrm{GC}$ attenuated with

Electronic supplementary material The online version of this article (https://doi.org/10.1007/s10072-020-04376-8) contains supplementary material, which is available to authorized users.

Tian Song

songtian1291@126.com

1 Department of Neurology, Beijing Tiantan Hospital, Capital Medical University, Beijing 100070, China

2 China National Clinical Research Center for Neurological Diseases, Beijing 100070, China relapses (secondly resistant) [2]. In recent years, several largescale databases reveal this point in real-world observational studies [3].

The mechanism governing the responsiveness of GC action remains elusive $[4,5]$. Multiple factors can influence cellular glucocorticoid sensitivity at the level of the glucocorticoid receptor (GR) and its signaling pathway, including cochaperones such as FK506-binding protein 5 (FKBP5) [6, 7]. The $G R$ gene can give rise to multiple splice variants: $\mathrm{GR} \alpha$ (the most abundant isoform), GR $\beta, \mathrm{GR} \gamma$. GR $\alpha$ is a transcription factor with transcriptional regulatory activity and essential to GC sensitivity regulation [8]. Researches in Caucasians report that polymorphisms of $G R$ result in a modified transcript, which may have an impact on GC sensitivity and disease course [9-11]. However, no research on Chinese MS patients has been conducted so far.

In this study, we detected $G R$ gene alterations in the entire coding regions in Chinese MS patients and aimed to elucidate the association of $G R$ gene and the GC response. We also investigated the differences in GR $\alpha$ and FKBP5 concentrations in $\mathrm{GC}$ responders and non-responders to explore possible strategies for modulation of glucocorticoid reactivity. 


\section{Methods}

\section{Patients}

A total number of 97 Chinese patients fulfilling the revised 2017 McDonald criteria for MS or clinical isolated syndrome (CIS) were included in this study [12]. Of them, 38 patients were diagnosed with CIS, whereas 44 with relapsingremitting MS (RRMS), 12 with secondary progressive MS (SPMS), and 3 with primary progressive MS (PPMS). All patients were in the acute attack and received glucocorticoid impulse therapy (methylprednisolone $500 \mathrm{mg}$ /days for 5 days). The Expanded Disability Severity Scale (EDSS) was assessed before the glucocorticoid impulse and 7 days after the therapy. Sixty-two patients responded to GC (the differences of EDSS before and after the GC impulse $\geq 0.5$ [13]), whereas 35 patients were non-responders (no differences in EDSS before and after the GC impulse [13]). The clinical data and characteristics of the patients are listed in Table 1.

This study was approved by the Ethics Committee of Beijing Tiantan Hospital, Capital Medical University, and written informed consent was obtained from all enrolled individuals.

\section{DNA extraction and sequence analysis}

Peripheral blood samples were taken on the day before GC impulse during active stage of disease. Genomic DNA was isolated from peripheral blood mononuclear cell (PBMC) using a whole-blood genomic DNA extraction kit (BioTeke, Beijing). The coding exons 2-9 of the GR gene (NM_001018077) were PCR-amplified by a LifeECO gene amplification instrument (BIOER, UK). The PCR products were bidirectionally sequenced employing an ABI 3730XL Genetic Analyzer (Life Technologies, USA). The primers used in the investigation are listed in the supplementary materials.

\section{ELISA assay}

GR $\alpha$ and FKBP5 levels were analyzed by ELISA in 20 serum samples in the GC-sensitive group and 18 in the resistant group. The levels of GR $\alpha$ and FKBP5 were measured on the same day before the GC treatment. Assays were performed following the instructions of the kit (Elabscience, E-EL-H1998c, CHN for GR $\alpha$ / AVIVA, OKEH00685, USA for FKBP5). Data were presented as the average of duplicate results.

\section{Statistical analysis}

Differences in the mutation distribution among GC responders and non-responders were analyzed by Fisher's exact test. Data were analyzed using independent sample $t$ test for normally distributed data (concentration of GR $\alpha$ ) and the Mann-Whitney test for non-normally distributed data (concentration of FKBP5). All statistical analysis was performed by IBM SPSS statistical software version 21.0 (IBM, Armonk, NY, USA). Values of $P<0.05$ were considered statistically significant.

\section{Results}

Whole-exome sequencing of the GR gene revealed 56 gene alterations, including 7 new unreported mutations and 49 single-nucleotide polymorphisms (SNPs), which are common in East Asian populations. All these seven mutations were located in exon 2 in the transcriptional activation region (TAR) of the GR gene, including five missense mutations and two premature termination codons (PTC) (Table 2). Six mutations were heterozygous and one mutation was homozygous. These seven mutations can cause changes in the coding amino acids and were predicted to be damaging or probably damaging by SIFT and Polyphen 2 software. Interestingly, unrelated patients No. 4 and No. 5 had an identical $\mathrm{A}>\mathrm{T}$ missense mutation on chromosomal chr5:142779668.

The mutation distributions in the MS patients based on their response to GCs (responders and non-responders) are presented in Table 3. No significant difference in the mutation distribution was detected between the responders and nonresponders to GC therapy $(P=0.416)$.

ELISA was performed to detect the serum GR $\alpha$ and FKBP5 levels before the GC impulse in patients with different
Table 1 Demographic and clinical characteristics of $97 \mathrm{MS}$ (CIS) patients

\begin{tabular}{lllll}
\hline & CIS & RRMS & SPMS \\
$n=38$ & $n=44$ & 12 & $\begin{array}{l}\text { PPMS } \\
n=3\end{array}$ \\
\hline Gender(male/female) & $17 / 21$ & $18 / 26$ & $3 / 9$ & $1 / 2$ \\
Age (year, M \pm SD) & $23.1 \pm 7.5$ & $32.9 \pm 6.7$ & $44.2 \pm 10.3$ & $37.7 \pm 8.4$ \\
EDSS before GC (M \pm SD) & $1.6 \pm 0.7$ & $2.8 \pm 1.3$ & $3.3 \pm 0.8$ & $3.5 \pm 1$ \\
EDSS after GC (M \pm SD) & $1.3 \pm 0.5$ & $2.5 \pm 1.1$ & $3.1 \pm 0.6$ & $3.5 \pm 1$ \\
\hline
\end{tabular}


Table 2 The seven mutations and patients' data

\begin{tabular}{llllllll}
\hline Patient & Gender & Age & Diagnosis & $\begin{array}{l}\text { EDSS } \\
\text { change }\end{array}$ & $\begin{array}{l}\text { Chromosomal } \\
\text { location }\end{array}$ & $\begin{array}{l}\text { Nucleotide } \\
\text { change }\end{array}$ & $\begin{array}{l}\text { Amino acid } \\
\text { change }\end{array}$ \\
\hline 1 & Male & 31 & CIS & 1 & chr5:142780172 & c.233T>C & p.L78P \\
2 & Female & 42 & RRMS & 1.5 & chr5:142779906 & c.499C $>$ T\# & p.Q167* \\
3 & Male & 70 & CIS & 0 & chr5:142779543 & c.862A>G & p.T288A \\
4 & Female & 38 & RRMS & 2 & chr5:142779668 & c.737A >T & p.K246M \\
5 & Male & 26 & CIS & 1.5 & chr5:142779668 & c.737A $>\mathrm{T}$ & p.K246M \\
6 & Female & 49 & CIS & 1 & chr5:142779822 & c.583C $>\mathrm{T}$ & p.Q195* \\
7 & Female & 64 & SPMS & 0.5 & chr5:142780253 & c.152C $>\mathrm{T}$ & p.A51V \\
\hline
\end{tabular}

\# indicate homozygous genotype
GC sensitivities. The GR $\alpha$ content in the serum of the sensitive group was significantly higher than that of the insensitive group ( $P=0.011$, Fig. 1a). The content of FKBP5 in the sensitive group was significantly lower than the one in the resistant group ( $P=0.025$, Fig. 1b). This result indicated that the high expression of GR $\alpha$ and the low expression of FKBP5 might be related to the increased sensitivity of GC.

\section{Discussion}

This study was designed to explore evidence for the possible correlation of $G R$ gene alterations with response to GC. This is the first sequencing of entire $G R$ coding exons in Chinese MS patients. We detected seven unreported mutations, whereas the presence or absence of mutations was independent of GC sensitivity. However, previously reported $G R$ polymorphisms and mutations related to GC sensitivity were not found [14-17]. To further elucidate the influencing factors of GR sensitivity, we compared the serum GR $\alpha$ and FKBP5 concentrations of GC-sensitive and GCresistant groups. Our findings showed that the GCsensitive patients had higher serum GR $\alpha$ and lower FKBP5 levels.

GC is the first-line therapy in acute attack of MS, and GR plays a critical role in the therapeutic effects of GC. Several $G R$ gene polymorphisms have been reported to be

Table 3 Mutation distributions in GC responders and non-responders

\begin{tabular}{llll}
\hline $\begin{array}{l}\text { Total patients } \\
(n=97)\end{array}$ & $\begin{array}{l}\text { Mutation } \\
\text { carriers } \\
(n=7)\end{array}$ & $\begin{array}{l}\text { Mutation } \\
\text { non-carriers } \\
(n=90)\end{array}$ & $P$ value \\
\hline $\begin{array}{l}\text { GC responders } \\
(n=62)\end{array}$ & $6(85.7 \%)$ & $56(62.2 \%)$ & 0.416 \\
$\begin{array}{l}\text { GC non-responders } \\
(n=35)\end{array}$ & $1(14.3 \%)$ & $34(37.8 \%)$ & \\
\hline
\end{tabular}

associated with either glucocorticoid hypersensitivity or glucocorticoid resistance (including BclI, N363S, ER22/ $23 E K, 9 \beta)$ in various diseases [16]. For example, van Winsen et al. established that ER22/23EK polymorphism was associated with a more aggressive MS phenotype, determined both clinically and on MRI [18]. A study on Guillain-Barre syndrome found that the disease in BclI and Tth111I carriers was more severe, whereas the BclI carriers only had a better prognosis [19]. However, none of the above polymorphisms was detected in any of our 97 MS patients. A possible reason for that outcome is the considerable variations in the frequency of the genotype among various races. The frequency of the G/A genotype of the $E R 22 / 23 E K$ polymorphism was $0.5 \%$ in a healthy Brazilian population and $0 \%$ in Asian and African subpopulations [20]. The absence of these polymorphisms in our results could be attributed to ethnic differences and the small sample size.

Many factors influence glucocorticoid sensitivity, including GC bioavailability, GR (gene polymorphisms, splice variant expression, transcriptional activity, and posttranslational modification), and the levels of chaperones and co-chaperones [6]. The $G R$ gene is merely one of the factors that influence glucocorticoid sensitivity. On the other hand, FKBP5, as one of the most important co-chaperones, can influence the ligand binding, resulting in changes in the clinical response to glucocorticoid treatment. The degree of dexamethasone-induced expression of FKBP51 in PBMC served as a marker for the clinical response to glucocorticoids in patients with asthma or rheumatoid arthritis [21, 22]. Currently, investigations are undergoing on the application of FKBP51 in drug development [23-25]. Inhibitor of FKBP5 may enhance GC sensitivity and serve as a new drug for GC-resistant patients with acute MS attack.

One of the limitations of this study was the incomplete number of serum samples subjected to ELISA assay; only 38 serum samples (out of 97 cases) were analyzed. Another important limitation was the fact that 
a

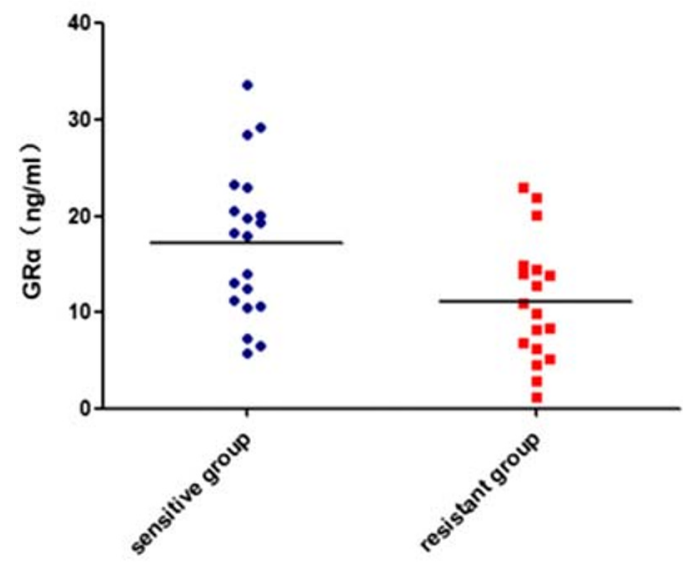

Fig. 1 GR $\alpha$ (a) and FKBP5 (b) serum concentration before GC impulse

frozen serum samples rather than PBMCs were available for this retrospective study. Therefore, we failed to perform flow cytometer assay of GR $\alpha$ and FKBP5 on the cellular level. In addition, the interval from the onset to the GC impulse was variable, which might have led to bias in the GC response and efficacy. Finally, EDSS changes were hardly detectable at higher values $(>3)$; MS functional composite (MSFC) or MS quality of life 54(MSQoL-54) $[26,27]$ may be more sensitive and suggestive. However, MSFC and MSQoL-54 were unavailable in our study.

In conclusion, the $G R$ mutations detected in our study were not associated with the response to GC in Chinese MS patients. The GC-sensitive patients had higher GR $\alpha$ but lower FKBP5 levels, which indicates inhibiting FKBP5 may improve GC efficacy for GC-resistant patients. Based on the findings of our study, we suggest that multiple complicated factors appear to be involved in the GC sensitivity regulation, which warrants further research to develop new drugs for MS.

Acknowledgments We thank the patients and their families who participated in this study for their support. We thank Dr. Decai Tian for his work in revision.

Funding information This research was supported by Grants from Capital Medical University Cultivation Fund (PYZ2018076 to Tian Song).

\section{Compliance with ethical standards}

Conflict of interest The authors declare that they have no conflicts of interest.

Ethical approval This study was approved by the Ethics Committee of Beijing Tiantan Hospital, Capital Medical University, and written informed consent was obtained from all enrolled individuals.

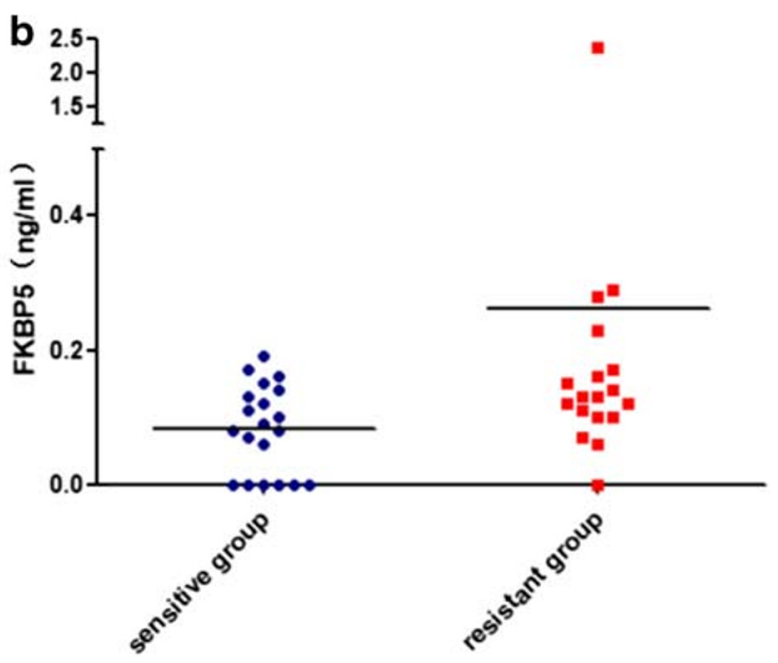

Open Access This article is licensed under a Creative Commons Attribution 4.0 International License, which permits use, sharing, adaptation, distribution and reproduction in any medium or format, as long as you give appropriate credit to the original author(s) and the source, provide a link to the Creative Commons licence, and indicate if changes were made. The images or other third party material in this article are included in the article's Creative Commons licence, unless indicated otherwise in a credit line to the material. If material is not included in the article's Creative Commons licence and your intended use is not permitted by statutory regulation or exceeds the permitted use, you will need to obtain permission directly from the copyright holder. To view a copy of this licence, visit http://creativecommons.org/licenses/by/4.0/.

\section{References}

1. Goodin DS (2014) Glucocorticoid treatment of multiple sclerosis. Handb Clin Neurol 122:455-464

2. Gold SM, Sasidhar MV, Lagishetty V, Spence RD, Umeda E, Ziehn MO, Krieger T, Schulz KH, Heesen C, Hewison M, Voskuhl RR (2012) Dynamic development of glucocorticoid resistance during autoimmune neuroinflammation. J Clin Endocrinol Metab 97(8): E1402-E1410

3. Trojano M, Bergamaschi R, Amato MP, Comi G, Ghezzi A, Lepore V, Marrosu MG, Mosconi P, Patti F, Ponzio M, Zaratin P, Battaglia MA, Italian Multiple Sclerosis Register Centers Group (2019) The Italian multiple sclerosis register. Neurol Sci 40(1):155-165

4. Cain DW, Cidlowski JA (2017) Immune regulation by glucocorticoids. Nat Rev Immunol 17(4):233-247

5. Ramamoorthy S, Cidlowski JA (2013) Exploring the molecular mechanisms of glucocorticoid receptor action from sensitivity to resistance. Endocr Dev 24:41-56

6. Quax RA, Manenschijn L, Koper JW, Hazes JM, Lamberts SW, van Rossum E, Feelders RA (2013) Glucocorticoid sensitivity in health and disease. Nat Rev Endocrinol 9(11):670-686

7. Fries GR, Gassen NC, Rein T (2017) The FKBP51 glucocorticoid receptor co-chaperone: regulation, function, and implications in health and disease. Int J Mol Sci 18(12) 
8. Caratti G, Matthews L, Poolman T, Kershaw S, Baxter M, Ray D (2015) Glucocorticoid receptor function in health and disease. Clin Endocrinol 83(4):441-448

9. Koper JW, van Rossum EF, van den Akker EL (2014) Glucocorticoid receptor polymorphisms and haplotypes and their expression in health and disease. Steroids. 92:62-73

10. van Winsen LL, Hooper-van Veen T, van Rossum EF, Polman CH, van den Berg T, Koper JW, Uitdehaag BM (2005) The impact of glucocorticoid receptor gene polymorphisms on glucocorticoid sensitivity is outweighted in patients with multiple sclerosis. J Neuroimmunol 167(1-2):150-156

11. van Winsen LM, Manenschijn L, van Rossum EF, Crusius JB, Koper JW, Polman CH, Uitdehaag BM (2009) A glucocorticoid receptor gene haplotype (TthIII1/ER22/23EK/9beta) is associated with a more aggressive disease course in multiple sclerosis. J Clin Endocrinol Metab 94(6):2110-2114

12. Thompson AJ, Banwell BL, Barkhof F, Carroll WM, Coetzee T, Comi G, Correale J, Fazekas F, Filippi M, Freedman MS, Fujihara K, Galetta SL, Hartung HP, Kappos L, Lublin FD, Marrie RA, Miller AE, Miller DH, Montalban X, Mowry EM, Sorensen PS, Tintoré M, Traboulsee AL, Trojano M, Uitdehaag BMJ, Vukusic S, Waubant E, Weinshenker BG, Reingold SC, Cohen JA (2018) Diagnosis of multiple sclerosis: 2017 revisions of the McDonald criteria. Lancet Neurol 17(2):162-173

13. Kassi E, Semaniakou A, Sertedaki A, Evangelopoulos ME, Kazazoglou T, Kominakis A, Sfagos C, Charmandari E, Chrousos GP, Moutsatsou P (2016) Sequencing analysis of the human glucocorticoid receptor (NR3C1) gene in multiple sclerosis patients. J Neurol Sci 363:165-169

14. van Oosten MJ, Dolhain RJ, Koper JW, van Rossum E, Emonts M, Han KH, Wouters JM, Hazes JM, Lamberts SW, Feelders RA (2010) Polymorphisms in the glucocorticoid receptor gene that modulate glucocorticoid sensitivity are associated with rheumatoid arthritis. Arthritis Res Ther 12(4):R159

15. Melief J, Koper JW, Endert E, Møller HJ, Hamann J, Uitdehaag BM, Huitinga I (2016) Glucocorticoid receptor haplotypes conferring increased sensitivity (BclI and N363S) are associated with faster progression of multiple sclerosis. J Neuroimmunol 299:84 89

16. Manenschijn L, van den Akker EL, Lamberts SW, van Rossum EF (2009) Clinical features associated with glucocorticoid receptor polymorphisms. An overview. Ann N Y Acad Sci 1179:179-198

17. Santen RJ, Jewell CM, Yue W, Heitjan DF, Raff H, Katen KS, Cidlowski JA (2018) Glucocorticoid receptor mutations and hypersensitivity to endogenous and exogenous glucocorticoids. J Clin Endocrinol Metab 103(10):3630-3639

18. van Winsen LM, Hooper-van Veen T, van Rossum EF, Koper JW, Barkhof F, Polman CH, Uitdehaag BM (2007) Glucocorticoid receptor gene polymorphisms associated with more aggressive disease phenotype in MS. J Neuroimmunol 186(1-2):150-155

19. Dekker MJ, van den Akker EL, Koper JW, Manenschijn L, Geleijns K, Ruts L, van Rijs W, Tio-Gillen AP, van Doorn P, Lamberts SW, Jacobs BC (2009) Effect of glucocorticoid receptor gene polymorphisms in Guillain-Barré syndrome. J Peripher Nerv Syst 14(2):7583

20. Souza MC, Martins CS, Silva-Junior IM, Chriguer RS, Bueno AC, Antonini SR, Silva WA Jr, Zago MA, Moreira AC, Castro Md (2014) NR3C1 polymorphisms in Brazilians of Caucasian, African, and Asian ancestry: glucocorticoid sensitivity and genotype association. Arq Bras Endocrinol Metabol 58(1):53-61

21. Chun E, Lee HS, Bang BR, Kim TW, Lee SH, Kim JH, Cho SH, Min KU, Kim YY, Park HW (2011) Dexamethasone-induced FKBP51 expression in peripheral blood mononuclear cells could play a role in predicting the response of asthmatics to treatment with corticosteroids. J Clin Immunol 31(1):122-127

22. Tajiri T, Matsumoto H, Niimi A, Ito I, Oguma T, Nakaji H, Inoue H, Iwata T, Nagasaki T, Kanemitsu Y, Petrova G, Mishima M (2013) Association of eosinophilic inflammation with FKBP51 expression in sputum cells in asthma. PLoS One 8(6):e65284

23. Ratajczak T, Cluning C, Ward BK (2015) Steroid receptorassociated immunophilins: a gateway to steroid signalling. Clin Biochem Rev 36(2):31-52

24. Maiarù $\mathrm{M}$, Morgan $\mathrm{OB}$, Mao $\mathrm{T}$, Breitsamer $\mathrm{M}$, Bamber $\mathrm{H}$, Pöhlmann M, Schmidt MV, Winter G, Hausch F, Géranton SM (2018) The stress regulator FKBP51: a novel and promising druggable target for the treatment of persistent pain states across sexes. Pain. 159(7):1224-1234

25. Kästle M, Kistler B, Lamla T, Bretschneider T, Lamb D, Nicklin P, Wyatt D (2018) FKBP51 modulates steroid sensitivity and NFKB signalling: a novel anti-inflammatory drug target. Eur J Immunol 48(11):1904-1914

26. Baldin E, Riise T, Mattarozzi K, Gajofatto A, Granella F, Leone M, Lugaresi A, Malagù S, Motti L, Neri W, Pesci I, Santangelo M, Scandellari C, Tola MR, Vignatelli L, Zenesini C, D'Alessandro R, G.E.Ro.N.I.Mu.S. study group (2019) Health-related quality of life in clinically isolated syndrome and risk of conversion to multiple sclerosis. Neurol Sci 40(1):75-80

27. Tacchino A, Brichetto G, Zaratin P, Battaglia MA, Ponzio M (2019) Self-assessment reliability in multiple sclerosis: the role of sociodemographic, clinical, and quality of life aspects. Neurol Sci 40(3): $617-620$

Publisher's note Springer Nature remains neutral with regard to jurisdictional claims in published maps and institutional affiliations. 